\title{
Improvement of direct torque control applied to doubly fed induction motor under variable speed
}

\author{
Hala Alami Aroussi ${ }^{1}$, EIMostafa Ziani ${ }^{2}$, Manale Bouderbala ${ }^{3}$, Badre Bossoufi ${ }^{4}$ \\ ${ }^{1,2}$ Laboratory of Electrical and Maintenance Engineering (LGEM), Mohamed Premier University, Morocco \\ ${ }^{3,4}$ LISTA Laboratory, Sidi Mohammed Ben Abdellah University, Morocco
}

\begin{tabular}{l} 
Article Info \\
\hline Article history: \\
Received Oct 28, 2018 \\
Revised Jul 31, 2019 \\
Accepted Nov 21, 2019 \\
\hline
\end{tabular}

Keywords:

DFIM

hysteresis controllers

DTC

\begin{abstract}
This work is dedicated to the study of an improved direct torque control of the doubly fed induction motor (DFIM). The control method adopts direct torque control 'DTC' because of its various advantages like the ease of implementation which allows a good performance at transient and steady state without PI regulators and rotating coordinate transformations. To do this, the modeling of the motor is performed. Subsequently, an explanation of the said command is spread out as well as the principle of adjusting the flux and the electromagnetic torque according to the desired speed. Then, the estimation method of these two control variables will be presented as well as the adopted switching table of the hysteresis controller model used based on the model of the multilevel inverters. Finally, the robustness of the developed system will be analyzed with validation in Matlab / Simulink environment to illustrate the performance of this control.
\end{abstract}

This is an open access article under the CC BY-SA license.

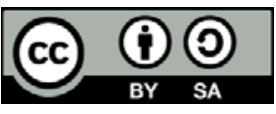

\section{Corresponding Author:}

Hala Alami Aroussi, Laboratory of Electrical and Maintenance Engineering (LGEM), Ecole Supérieur de Technologie, Mohamed Premier University, BP 473 Complexe universitaire Al Qods, Oujda 60000 Oujda, Morocco Email : h.alamiarroussi@ump.ac.ma, alami.aroussi.hala@gmail.com

\section{INTRODUCTION}

Over the last decades, the technique of variable speed electric drives has been developed rapidly thanks to advances in power electronics and the technical advantages that an asynchronous machine offers over a DC machine, such as the robustness of the machine and its low cost of purchase and maintenance.

Also, one of the latest developed strategies is direct torque regulation. This technique was initiated during the 1980s by Takahashi and Depenbrock as competitive with conventional controls, based on pulse width modulation (PWM) power supply, decoupling of the flux and by the orientation of the magnetic flux.

These direct control methods belong to the category of amplitude control and were originally designed for a two-level inverter [1]. The direct control of the torque (DTC) consists of controlling directly the closing or opening of the inverter switches from the precalculated values of the stator flux and the couple. The changes of states of the switches are related to the evolution of the electromagnetic states of the engine.

The main goal of this work is to present an advanced method of direct torque control applied to DFIM shown schematically in the following figure by using multilevel inverters that offer huge advantages over inverters with 2-levels [2].

Thus, the distribution of the voltage in the multi-level inverters is obtained in a natural way in steady-state, which makes it possible to switch each semiconductor independently of the others.

This makes the converter more robust and more performance during switching. Also, the switched voltage is at the reduced amplitude and the switching is therefore easier to manage. On the machine side: the number of 
voltage generated by a multilevel inverter is higher than that of the inverter with 2-voltage levels, which will allow to improve the quality of its waveform and will manifest itself by reducing its harmonic distortion. This will also result in the decrease of iron losses, the increase in the life of insulators or the reduction of the electromagnetic radiation from the windings of the machine.

In this perspective, a complete study of the architecture is proposed in order to elaborate the improved direct control of the torque law [3-5]. Then, the whole system is validated under the Matlab / Simulink environment to ensure the efficiency of the control.

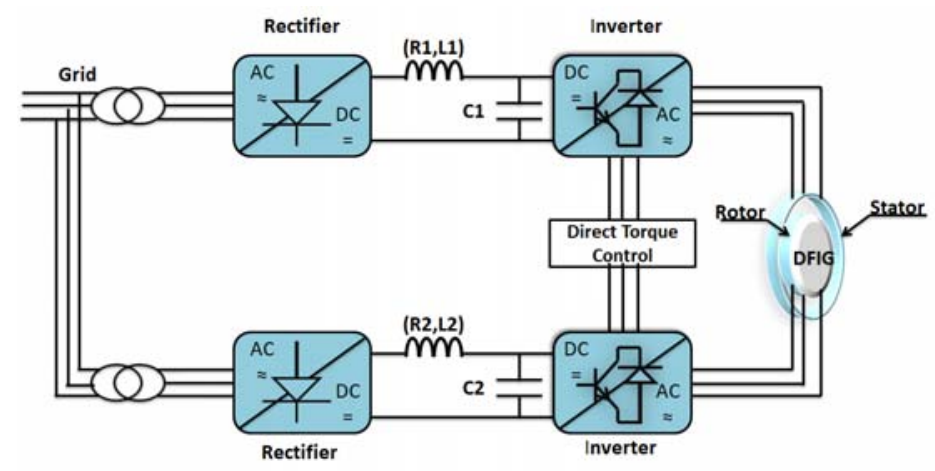

Figure 1. Synopsis of the DTC of the DFIM

\section{DOUBLY FED INDUCTION MOTOR MODELING:}

In the literature, we find that the DFIM model in the reference $\alpha \beta$ is summarized in three types of equations: electrical, magnetic and electromagnetic[6, 7].

\subsection{Electrical equations:}

In the frame $\alpha \beta$, the stator and rotor voltages are expressed by the following equations:

$$
\left\{\begin{array}{l}
V_{s \alpha}=R_{s} i_{s \alpha}+\frac{d \psi_{s \alpha}}{d t} \\
V_{s \beta}=R_{s} i_{s \beta}+\frac{d \psi_{s \beta}}{d t} \\
V_{r \alpha}=R_{r} i_{r \alpha}+\frac{d \psi_{r \alpha}}{d t}+\left(\omega_{s}-\omega_{r}\right) \psi_{r \beta} \\
V_{r \beta}=R_{r} i_{r \beta}+\frac{d \psi_{r \beta}}{d t}-\left(\omega_{s}-\omega_{r}\right) \psi_{r \alpha}
\end{array}\right.
$$

\subsection{Flux equations:}

The stator and rotor fluxes are given by:

$$
\left\{\begin{array}{l}
\psi_{s \alpha}=L_{s} i_{s \alpha}+M i_{r \alpha} \\
\psi_{s \beta}=L_{s} i_{s \beta}+M i_{r \beta} \\
\psi_{r \alpha}=L_{r} i_{r \alpha}+M i_{s \alpha} \\
\psi_{r \beta}=L_{r} i_{r \beta}+M i_{s \beta}
\end{array}\right.
$$

Where:

$R_{S}$ and $R_{r}:$ Resistances of a phase of the stator/rotor.

$L_{s}=l_{s}-M_{s}$ and $L_{r}=l_{r}-M_{r}$ : Cyclic inductances of a stator/rotor phase.

$M$ : Maximum mutual inductance between a stator/rotor phase.

$\omega_{r}$ and $\omega_{s}$ : Angular speed of the rotor/stator.

\subsection{Electromagnetic torque:}

The equation of the electromagnetic torque as a function of the stator flux and stator current is given by the expression below:

Int J Pow Elec \& Dri Syst Vol. 11, No. 1, Mar 2020 : 97 - 106 


$$
T_{e m}=\frac{3}{2} p\left(i_{s \alpha} \psi_{s \beta}-i_{s \beta} \psi_{s \alpha}\right)
$$

\section{DIRECT TORQUE CONTROL:}

\subsection{Principle of the control:}

Direct torque control of an asynchronous machine is based on the direct determination of the control sequence applied to the switches of the static power converter in order to impose the desired levels of torque and flux [8]. The objective of a DTC is to maintain the electromagnetic torque and the module of the stator flux inside the hysteresis bands by choosing the output voltage of the inverter. When the torque or the module of the stator flux reaches the upper or lower limit of the hysteresis, an appropriate voltage vector is applied to bring the quantity concerned inside its hysteresis band. To choose the voltage vector, it is essential to know the rules for the evolution of the torque and the stator flux module [9-10].

In the complex plane consisting of the axes $(\alpha \beta)$, the complex voltage vector representing the state of a three-phase voltage inverter can have only eight distinct positions because each of the three arms of the inverter can only have two possible states. The vector voltage is then defined by the following relation [11]:

$$
\bar{V}=V_{\alpha}+j V_{\beta}=\sqrt{\frac{2}{3}} U_{D C}\left(V_{a}+V_{b} e^{j \frac{2 \pi}{3}}+V_{c} e^{j \frac{4 \pi}{3}}\right)
$$

Where: $\mathrm{V}_{\mathrm{a}}, \mathrm{V}_{\mathrm{b}}$ and $\mathrm{V}_{\mathrm{c}}$ are the output voltages of the inverter.

The expression of stator flux in the reference frame linked to the stator of the machine is obtained by the following equation :

$$
\left\{\begin{array}{l}
\psi_{s \alpha}=\int_{0}^{t}\left(V_{s \alpha}-R_{s} i_{s \alpha}\right) d t \\
\psi_{s \beta}=\int_{0}^{t}\left(V_{s \beta}-R_{s} i_{s \beta}\right) d t
\end{array}\right.
$$

\subsection{Hysteresis Controller:}

The main objective of the direct torque control is to maintain the instant stator flux and electromagnetic torque in a specific band. The DTC is based on two hysteresis comparators which use as input the error signals between the reference values and estimates of the stator flux and electromagnetic torque. These two controllers are responsible for deciding how much a new switch and/or output voltage vector of the inverter is applied.

If the errors $\left(e \psi_{r}\right.$ or $\left.e T\right)$ is increasing and reaches a higher level, the hysteresis controller switches its output on '1'.

\subsection{Vector Selection:}

From the vectors of the voltages schematized in Figure 2 we can distinguish four groups of vectors: 1) The group of vectors "zero tension": They are obtained by three different combinations of the states of the three arms of the inverter [12-15]: $(1,1,1),(-1,-1,-1)$ and $(0,0,0)$ named respectively $V_{7}, V_{14}$ and $V_{0}$. 2) The group of the vectors "half tension" that we can decompose into 2 other subgroups:

- The first consists of the vectors: $\mathrm{V}_{1}, \mathrm{~V}_{2}, \mathrm{~V}_{3}, \mathrm{~V}_{4}, \mathrm{~V}_{5}$ and $\mathrm{V}_{6}$.

- The second groups the vectors: $\mathrm{V}_{8}, \mathrm{~V}_{9}, \mathrm{~V}_{10}, \mathrm{~V}_{11}, \mathrm{~V}_{12}$ and $\mathrm{V}_{13}$. These vectors constitute the internal hexagon "half tension.

3) The group of "full voltage" vectors: This group contains the voltages vectors named: $V_{15}, V_{16}, V_{17}, V_{18}$, $\mathrm{V}_{19}$ and $\mathrm{V}_{20}$. These vectors constitute the external hexagon of "full voltage".

4) The group of "intermediate voltages": the vectors of the voltages of this group are called $V_{21}, V_{22}, V_{23}, V_{24}$, $\mathrm{V}_{25}$ and $\mathrm{V}_{26}$. 


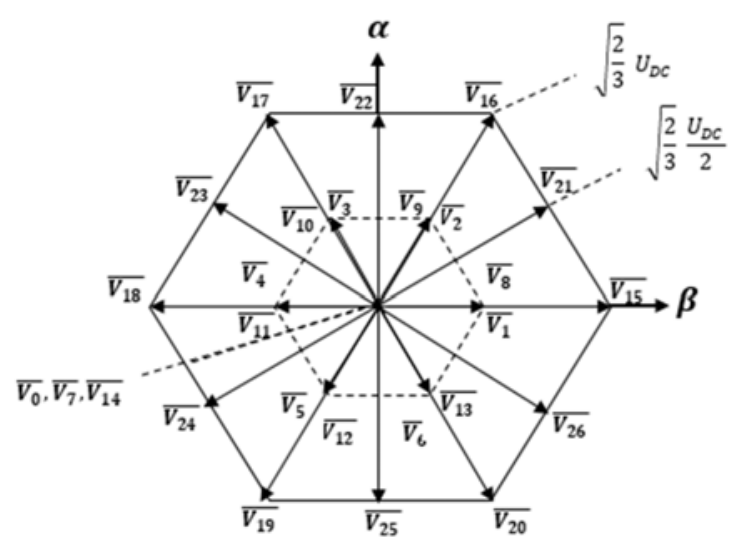

Figure 2.Vector of tensions in the frame $(\alpha \beta)$

\subsection{Switching table:}

The switching table selects the appropriate voltage vector of the inverter in order to orient the stator flux and electromagnetic torque in their desired values, also based on the position of the source voltage vector and the errors of the stator flux and electromagnetic torque [16, 17]. In this work, we adopted a modified switching table compare to ensure optimal minimization in error.

\section{APPLICATIONS AND RESULTS:}

The following figure describes the model used for the control of the doubly-fed induction motor in Matlab/Simulink environment [18-21]:

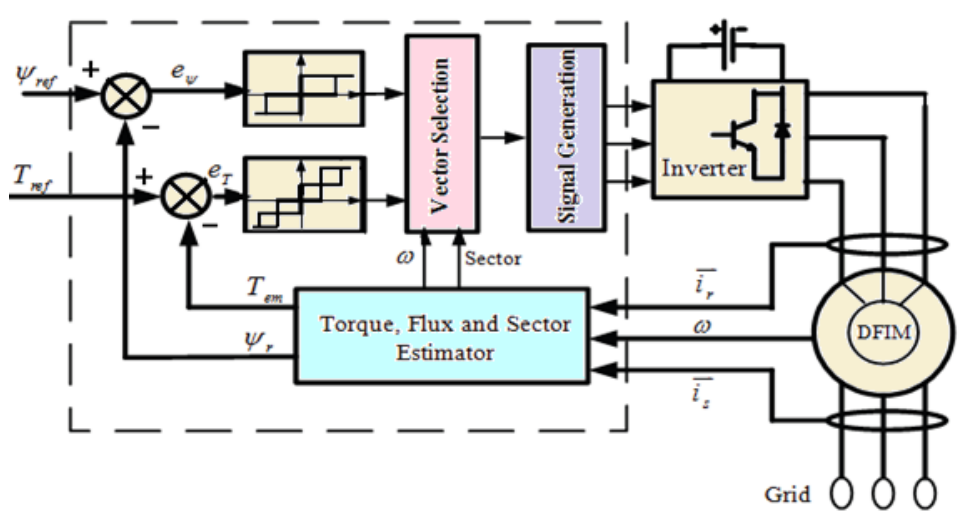

Figure 3.Direct torque control (DTC) block diagram

\subsection{Setpoint tracking test:}

The system is analyzed during steady-state and transients conditions at variable speed (subsynchronous, synchronous and super-synchronous). The results of the simulation are summarized in Figure 6 $[22,23]$ : 


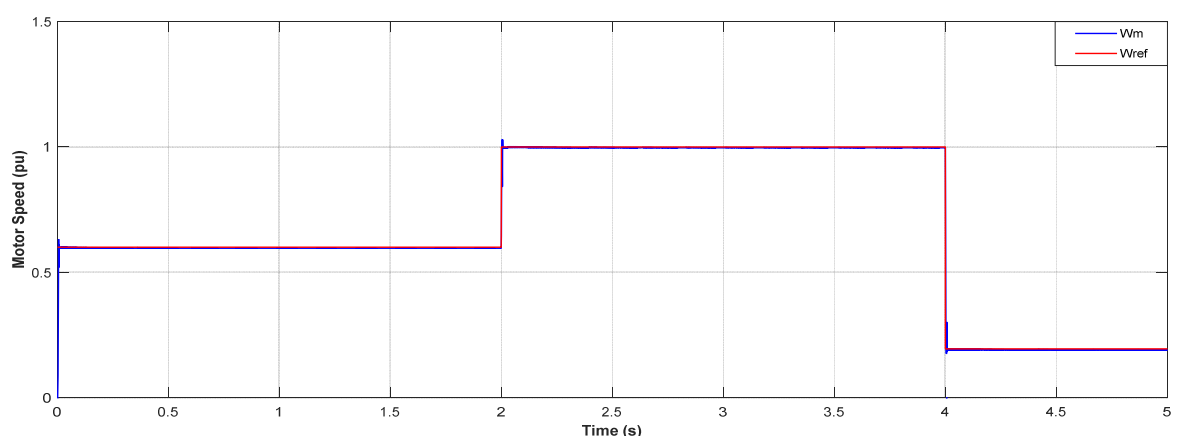

(a)

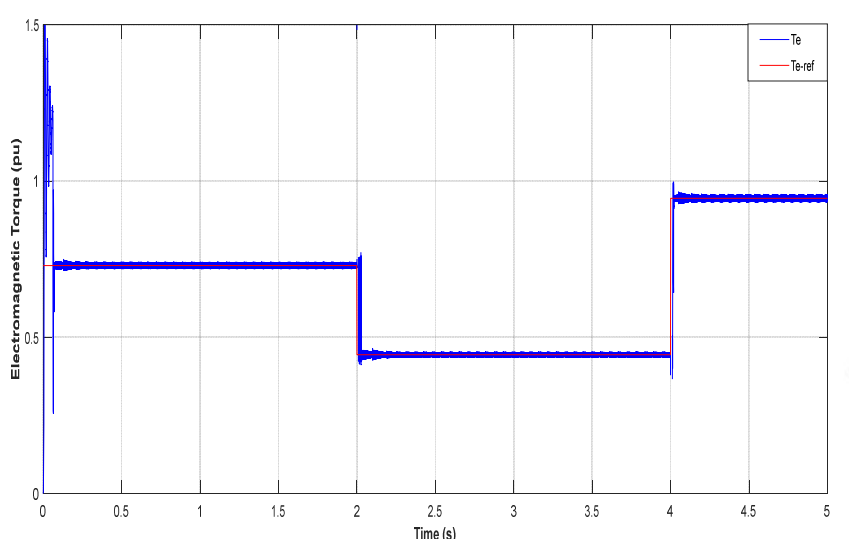

(b)

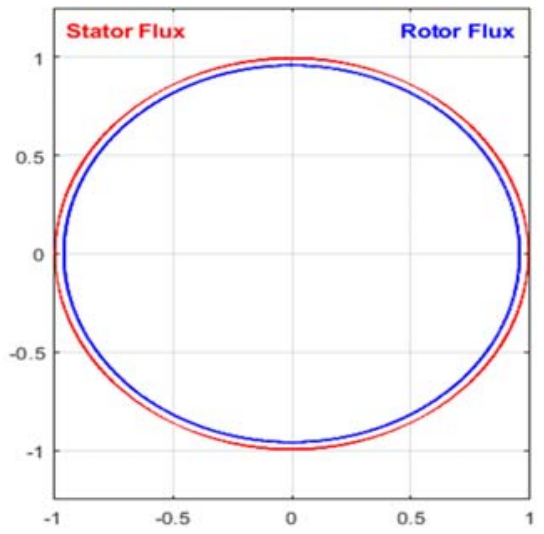

(c)

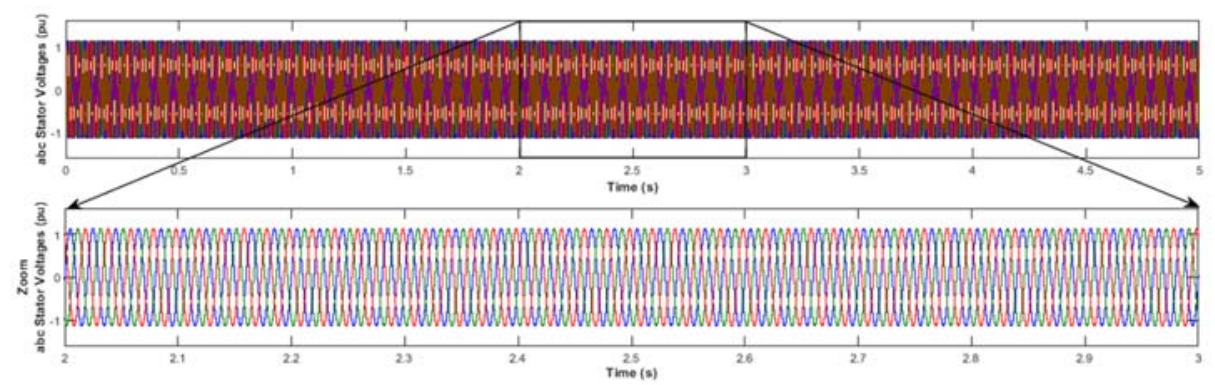

(d)

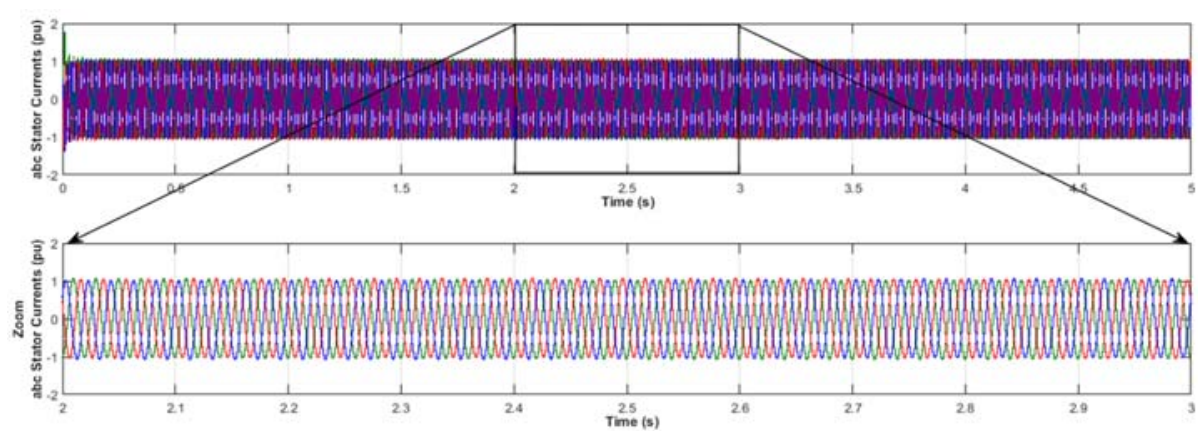

(e) 


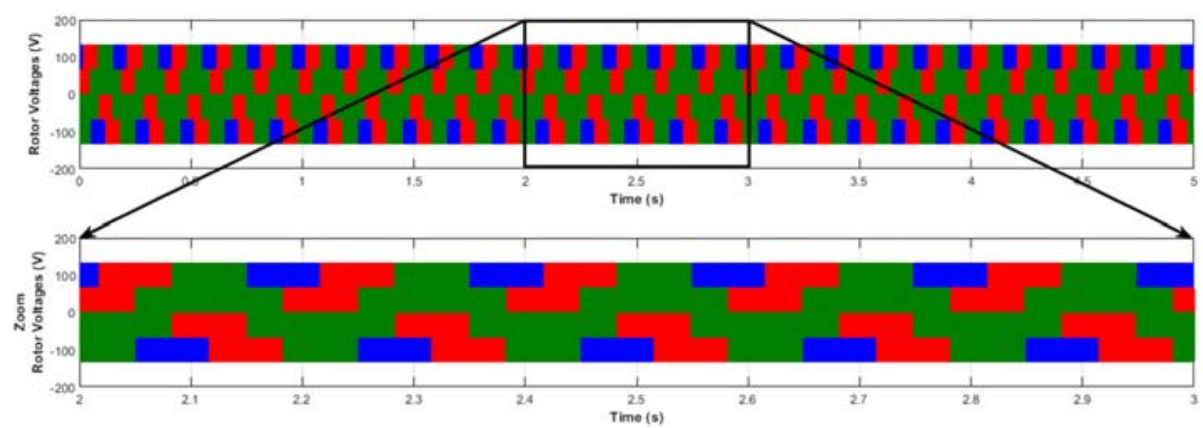

(f)

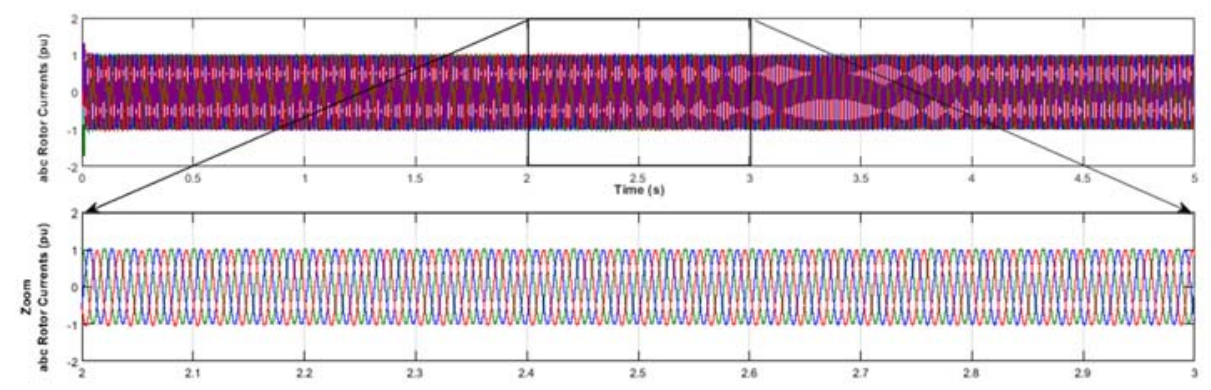

(g)

Figure 6. (a) Curves of: the rotational speed, (b) the electromagnetic torque, (c) the stator and rotor fluxes, (d) the voltages of the stator, (e) the currents of the stator, (f) the voltages of the rotor, (g) the currents of the rotor.

\subsection{Robustness Test:}

The parameters of the DFIM are exposed to variations caused by various changes such as temperature increase, skin effect, etc. In this case, the proposed direct torque control must guarantee good results regardless of the parameter variations $[24,25]$ : conditions:

So, the robustness of the command used (DTC) has been tested according to the following

Resistance $\mathrm{R}_{\mathrm{s}}$ multiplied by 2

Inductances $L_{s}$ and $L_{r}$ multiplied by 0.5 .

Figure 7 shows the simulation's results obtained:

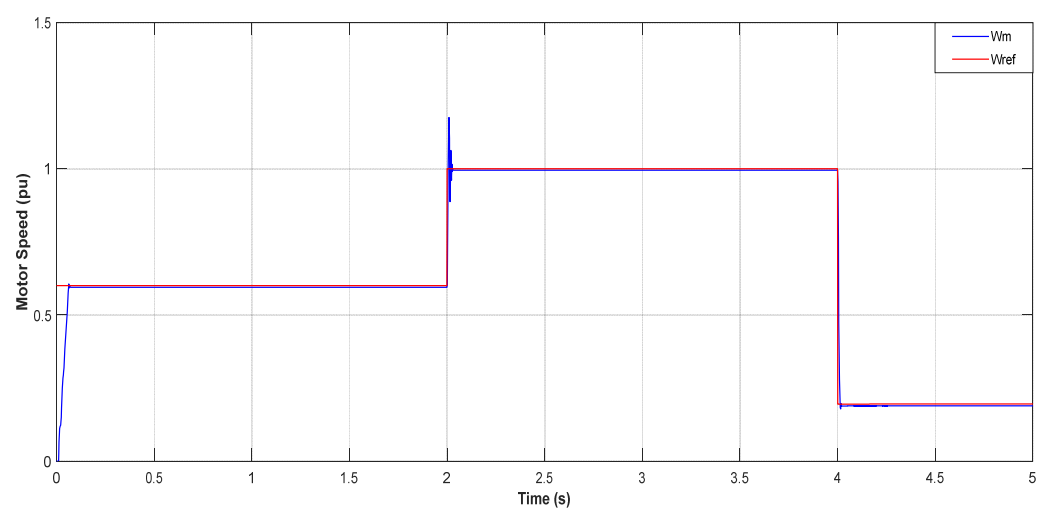

(a) 


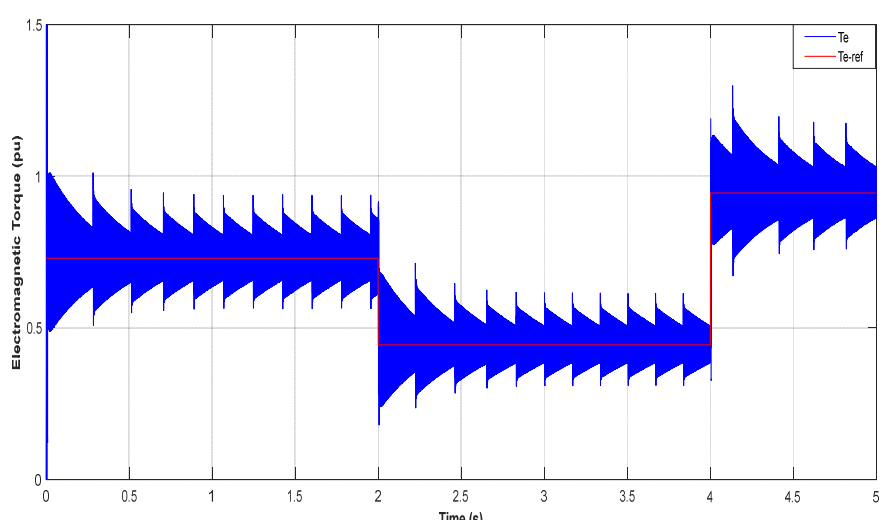

(b)

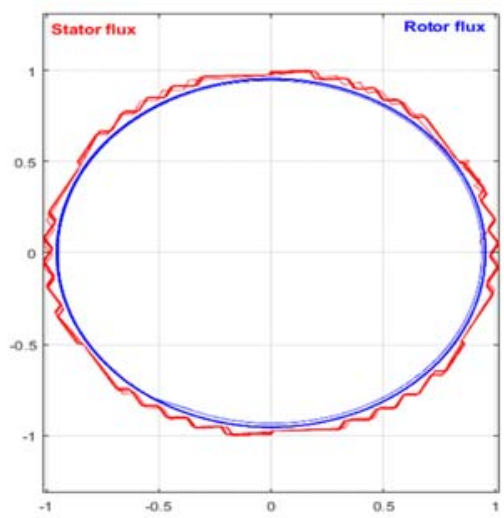

(c)

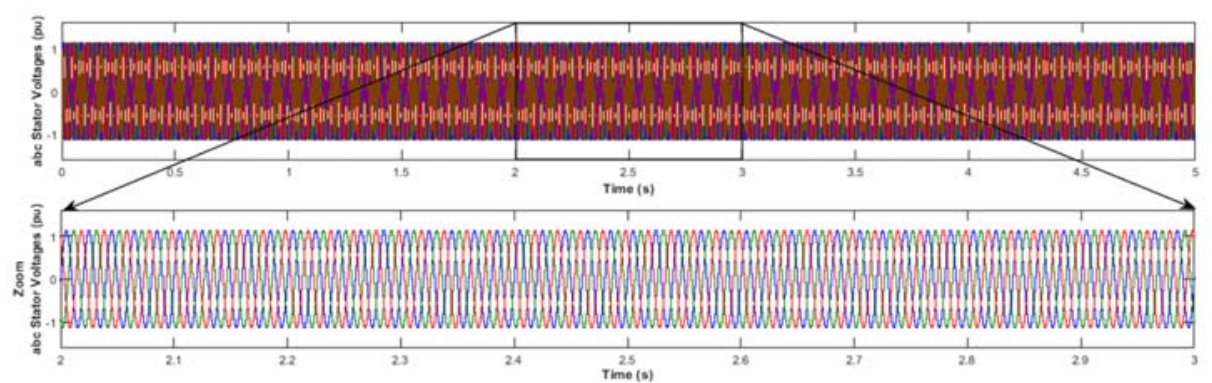

(d)

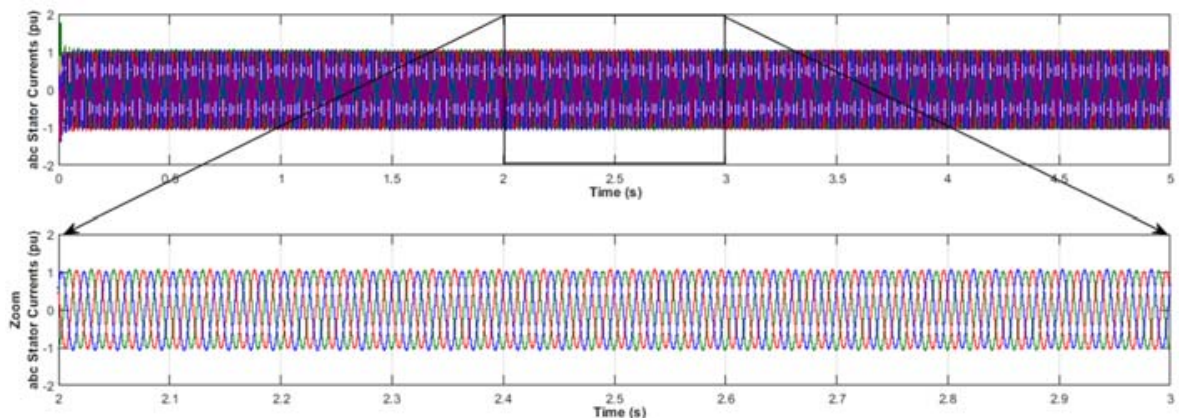

(e)

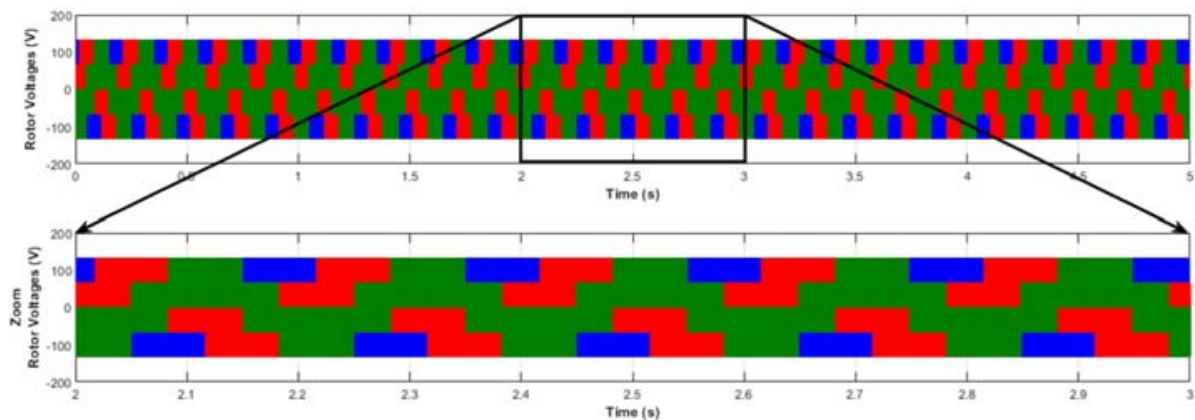

(f) 


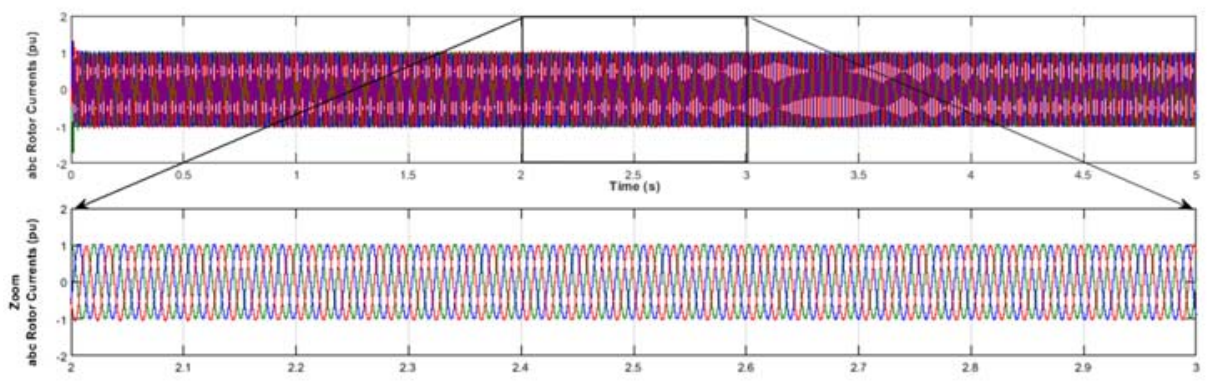

(g)

Figure 7. (a) Curves of: rotational speed, (b) the electromagnetic torque, (c) the stator and rotor fluxes, (d) the voltages of the stator, (e) the currents of the stator, (f) the voltages of the rotor, (g) the currents of the rotor.

Comparing the results of the simulations illustrated in Figure 6 and Figure 7, we can ensure, even by changing the initial values of DFIM, that:

- The rotational speed follows its reference.

- The stator flux has a circular trajectory since it is supplied by a sinusoidal voltage from the grid. Though, there is a ripple superimposed on the circular trajectory of the rotor flux due to the hysteresis band chosen in the direct torque control.

- The electromagnetic torque follows its reference with fewer oscillations and disturbances due to the hysteresis controller and the change of the initial parameters of the machine.

- The stator and rotor currents in the frame $(a, b, c)$ have a sinusoidal shape despite the fact that the behavior of the electromagnetic torque changes.

From these results, we can conclude that the direct torque control has a low response time in the transient regime, and fewer disturbance oscillations in the curves of the various curves that quickly regain their reference values.

\section{CONCLUSION:}

This work put forward an enhancement of the classical direct torque control using a multi-level inverter in order to have a large switching table. The use of such a kind of table allows us to increase and decrease the module of the fluxes and the electromagnetic torque as well. The results (setpoint tracking and robustness test) in steady and transient regimes show a complete correlation. They both prove the robustness and efficiency of the method developed.

In general, the simulation results obtained during the application of the control under variable speed show excellent dynamic performance and tracking ability of the fluxes and the electromagnetic torque generated at the corresponding reference values with the preservation of sinusoidal shapes for both currents and voltages (stator and rotor).

\section{APPENDIX:}

Table 2. Parameters of the doubly fed induction motor

\begin{tabular}{cc}
\hline \multicolumn{1}{c}{ DFIM PARAMETERS } \\
\hline Nominal Power & $\mathrm{Pn}=1.5 \mathrm{KW}$ \\
Stator Voltage & $\mathrm{Vs}=220 / 380 \mathrm{~V}$ \\
Stator Frequency & $\mathrm{fs}=50 \mathrm{~Hz}$ \\
Stator Resistance & $\mathrm{Rs}=1.18 \Omega$ \\
Stator Inductance & $\mathrm{Ls}=0.4 \mathrm{H}$ \\
Rotor Resistance & $\mathrm{Rr}=1.66 \Omega$ \\
Rotor Inductance & $\mathrm{Lr}=0.18 \mathrm{H}$ \\
Mutual Inductance & $\mathrm{M}=0.17 \mathrm{H}$ \\
No. of Pair of Poles & $\mathrm{P}=2$ \\
\hline
\end{tabular}

Int J Pow Elec \& Dri Syst Vol. 11, No. 1, Mar 2020 : 97 - 106 


\section{REFERENCES}

[1] Wang, F.; Zhang, Z.; Mei, X.; Rodríguez, J.; Kennel, R. “Advanced Control Strategies of Induction Machine: Field Oriented Control, Direct Torque Control and Model Predictive Control." Energies 2018, 11, 120.

[2] H.Alami Aroussi, EL.M. Ziani, B.Bossoufi "Contribution to the enhancement of dual DTC Application: Doubly fed induction motor" International Conference On Advanced Technologies For Signal\& Image Processing ATSIP'2017, May 22 - 24, 2017, Fez, Morocco.

[3] Lachtar Salah, Ghoggal Adel, Koussa Khaled, Bouraiou Ahmed, Attoui Issam "Broken rotor bar fault diagnostic for DTC Fed induction motor using stator instantaneous complex apparent power envelope signature analysis" IJPEDS International Journal of Power Electronics and Drive System (IJPEDS), pp 1187-1196 Vol.10 No.3, September 2019.

[4] Draoui Abdelghani, Allaoua Boumediène "Direct Torque Control of Two Induction Motors Using the Nine-Switch Inverter" " IJPEDS International Journal of Power Electronics and Drive System (IJPEDS), pp 1552-1564 Vol.9 No.4, December 2018.

[5] H.ALAMI AROUSSI, El.M.ZIANI, M.BOUDERBALA, B.BOSSOUFI "Enhancement Of The Direct Power Control Applied to DFIG-WECS" International Journal of Electrical and Computer Engineering (IJECE), Vol.10 No.1, pp.35-46, February 2020.

[6] D. Roye, "Modélisation, contrôle vectoriel et DTC ", HERMES Science Europe Ltd, 2000, sous la direction de Carlos Canudas de Wit, pp. 81 -132 vol.1

[7] Abad G, Lopez J, Rodriguez M, Marroyo L, Iwanski G. "Doubly Fed Induction Machine: Modeling and Control for Wind Energy Generation,” 1st ed., Hoboken, New Jersey, USA: Wiley-IEEE Press; 2011, ISBN: 978-0-470-768655 .

[8] A. Nabae, I. Takahashi, and H. Akagi, "A new neutral point clamped PWM inverter," IEEE Transaction on Industry Applications; Vol.IA-17, No.5, pp.518-523, September- October 1981.

[9] I. Takahashi and T. Noguchi, "A new quick-response and high-efficiency control strategy of an induction motor," IEEE Trans. Ind. Appl., Vol.IA-22, No.5, October pp.820-827, 1986.

[10] Seok Ho Jeon, Student, Kwang Kyo Oh, and Jin Young Choi, "Flux Observer with Online Tuning of Stator and Rotor Resistances for Induction Motors," IEEE Transactions On Industrial Electronics, Vol. 49, No. 3, June 2002.

[11] Y. Djeriri, A. Meroufel, B. Belabbes and A. Massoum, "Three-level NPC voltage source converter based direct power control of the doubly fed induction generator at low constant switching frequency;" Revue des Energies Renouvelables, Centre de Développement des Energies Renouvelables- CDER, Algérie, Vol.16, No.1, pp.91- 103, 2013.

[12] Rachid, D; Othman, H.; Faouzi, B., “ A Completely Vectored Direct Torque Control Scheme for Induction Motor”, Systems, Man and Cybernetics, IEEE International Conference, vol.5, Issue , 6-9 oct., 2002

[13] B.Bossoufi, M.Karim, S.Ionita, A.Lagrioui, "The Optimal Direct Torque Control of a PMSM drive: FPGA-Based Implementation with Matlab \& Simulink Simulation" Journal of Theoretical and Applied Information Technology JATIT, Vol. 28, No.2, pp63-72, 30th June 2011.

[14] Buja, G.; Casadei, D.; Serra, G., "Direct torque control of induction motor drives" , Proceedings of The IEEE International Symposium, Issue, 7-11 Jul 1997 Page(S):Tu2 - Tu8 Vol.1

[15] Nik Rumzi Nik Idris, and Abdul Halim Mohamed Yatim, "Direct Torque Control of Induction Machines with Constant Switching Frequency and Reduced Torque Ripple", IEEE Transactions on Industrial Electronics, Vol. 51, No. 4, August 2004.

[16] Pura, P, Iwanski, G. Direct torque control of a doubly fed induction generator working with unbalanced power grid. Int Trans Electr Energ Syst. 2019; 29:e2815.

[17] Iwanski G, Pura P, Luszczyk T. "Properties and control of variable speed doubly fed induction generator." 2015 tenth Int. Conf. Ecol. Veh. Renew. Energies, pp. 1-8, 2015.

[18] Xiong P, Sun D. "Backstepping-based DPC strategy of a wind turbine-driven DFIG under normal and harmonic grid voltage." In IEEE Trans. Power Electrons. Vol.31, No. 6, pp. 4216-4225, 2016.

[19] Song Y, Nian H. "Modularized control strategy and performance analysis of DFIG system under unbalanced and harmonic grid voltage". IEEE Trans Power Electron. Vol. 30, No. 9, pp. 4831-4842, 2015.

[20] Y. Errami, A. Obbadi, S. Sahnoun, M. Barara, M. Ouassaid, and M. Maaroufi, "Control of High-Power Wind Energy Conversion System Fed by Multi-level Converters," Energy Procedia, vol. 119, pp. 214-227, 2017.

[21] A. Zemmit, S. Messalti, and A. Harrag, "A new improved DTC of doubly fed induction machine using GA-based PI controller," Ain Shams Eng. J., pp. 0-8, 2016.

[22] C. Balasundar, S. Sudharshanan, and R. Elakkiyavendan, "Design of an Optimal Tip Speed Ratio Control MPPT Algorithm for Standalone WECS," Int. J. Res. Appl. Sci. Eng. Technol., vol. 3, no. V, 2015.

[23] Peña R, Cárdenas R, Asher G. "Overview of control systems for the operation of DFIGs in wind energy applications." IECON 2013-39th Annual Conference of the IEEE Industrial Electronics Society, Vienna, 2013, pp. 88-95.

[24] Y. Li et al., "An Improved DTC Controller for DFIG-Based Wind Generation System," in 2016 IEEE 8th International Power Electronics and Motion Control Conference, pp. 6-9, 2016.

[25] M. R. Agha Kashkooli, S. M. Madani, and R. Sadeghi, "Improved Direct Torque Control of DFIG with reduced torque and flux ripples at constant switching frequency," in 7th Power Electronics, Drive Systems and Technologies Conference, PEDSTC 2016, no. Pedstc, pp. 58-63, 2016. 


\section{BIOGRAPHIES OF AUTHORS}

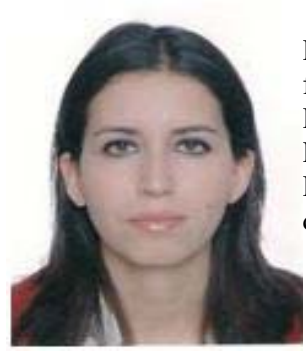

Hala ALAMI AROUSSI received her M.S degree in Industrial Automated Systems Engineering from Sidi Mohammed Ben Abdellah University, Fez, Morocco. She is currently pursuing her Ph.D in Electrical Engineering - Renewable Energy at Mohamed Premier University, Oujda, Morocco. She is a member of the laboratory of electrical engineering and maintenance (LGEM). Her research interests include modeling, control of wind energy conversion systems applied to a doubly fed induction machine using DSPACE.

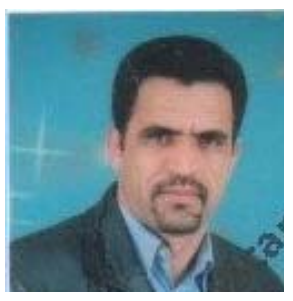

Elmostafa ZIANI received his $\mathrm{PhD}$ in Electrical Engineering from Abdelmalek Essaadi University, Tangier, Morocco. Currently, he is the director of the Applied Engineering Department of the Ecole Supérieur de Technologie-Oujda and a member of the the laboratory of electrical engineering and maintenance.

$\mathrm{He}$ is author of several articles dealing with the application of intelligent instrumentation to the monitoring of complex systems, industrial systems and the contribution to the control and optimization of electrical conversion systems "wind and photovoltaic".

His research interests include electrical engineering, power electronics and automation.

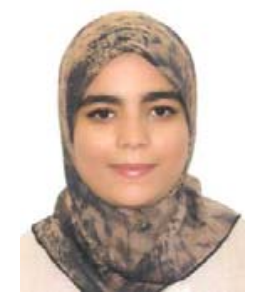

BOUDERBALA Manale is a Ph.D. Student in Electrical Engineering from the Faculty of Sciences Dhar El Mahraz, Sidi Mohammed Ben Abdellah University, Fez - Morocco. She is member of LISTA Laboratory. She had her master's degree in Engineering of Industrial Automated Systems at the Faculty of Sciences Dhar el Mahrez Fez. Her research interests include Renewable Energy, static converters, electrical motor drives, and power electronics.

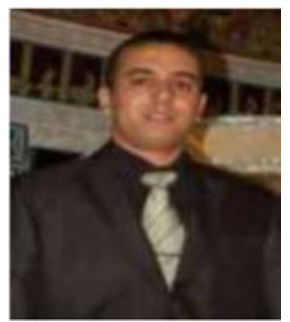

Badre BOSSOUFI was born in Fez city, Morocco, on May 21, 1985. He received the Ph.D. degree in Electrical Engineering from University Sidi Mohammed Ben Abdellah, Faculty of Sciences, Morocco and PhD. degree from University of Pitesti, Faculty of Electronics and Computer, Romanie and Montefiore Institute of electrical engineering, Luik, Belgium, in 2013. $\mathrm{He}$ is a Professor of Electrical Engineering, at the LISTA Laboratory Faculty of Sciences Dhar El Mahraz, Sidi Mohammed Ben Abdellah University, Fez - Morocco. His research interests include static converters, electrical motor drives, power electronics, Smart Grid, Renewable Energy and Artificial Intelligent. 